\title{
On the Role of Electrodes in Introducing Airflow Distortion in Residential Oil Burners
}

\author{
Mebougna L. Drabo', Narinder K. Tutu ${ }^{2}$, Thomas Butcher ${ }^{2}$, Rebecca Trojanowski², \\ Stephen U. Egarievwe ${ }^{3}$ \\ ${ }^{1}$ Department of Mechanical \& Civil Engineering, and Construction Management, Alabama A \& M University, \\ Normal, AL, USA \\ ${ }^{2}$ Sustainable Energy Technology Department, Brookhaven National Laboratory, Upton, NY, USA \\ ${ }^{3}$ Department of Electrical Engineering and Computer Science, Alabama A\&M University, Normal, AL, USA \\ Email: mebougna.drabo@aamu.edu
}

How to cite this paper: Drabo, M.L., Tutu, N.K., Butcher, T., Trojanowski, R. and Egarievwe, S.U. (2019) On the Role of Electrodes in Introducing Airflow Distortion in Residential Oil Burners. Engineering, 11, 260-271.

https://doi.org/10.4236/eng.2019.115019

Received: April 8, 2019

Accepted: May 14, 2019

Published: May 17, 2019

Copyright $\odot 2019$ by author(s) and Scientific Research Publishing Inc. This work is licensed under the Creative Commons Attribution International License (CC BY 4.0).

http://creativecommons.org/licenses/by/4.0/

\begin{abstract}
Computational Fluid Dynamics (CFD) simulations of airflow through a retention head residential oil burner were carried out to study the velocity field near and around the fuel spray. The simulations revealed (as expected, based on some previous experimental measurements) the velocity flow field to be far from axisymmetric. Moreover, the center of the swirling airflow was found to be at some radial distance away from the physical centerline of the flame tube. Since it was suspected that the two electrodes just upstream of the retention ring of the burner might be responsible for this flow distortion, additional CFD simulations were then carried out for the cases of no electrodes and 4 -electrodes. The results clearly show that all flow distortions (velocity deviations from axisymmetric value) vanish when no electrodes are present and that the flow distortions are reduced by a factor of 2 when two additional dummy electrodes (for a total of 4 electrodes) are included in the burner design. Furthermore, for the 4-electrode case, the eccentricity of the swirling airflow is reduced by almost a factor of 3 as compared to the base design case of 2-electrodes.
\end{abstract}

\section{Keywords}

Flow Distortion, Residential Oil Burner, Retention Head, Flame Tube, Swirl Airflow

\section{Introduction}

Residential oil burners are devices that provide hot water and home heating for houses. These typically utilize \#2 heating oil as fuel which is supplied under 
pressure via a pump. A schematic of the main components of such oil burners is shown in Figure 1. A single electric motor drives both the fuel pump and the high-speed fan that supplies the combustion air for the burner. The fuel pump supplies the heating oil to a pressure swirl nozzle resulting in a fine fuel droplet spray in the flame tube of the burner. Simultaneously, combustion air is directed towards the flame tube via a retention head which is located just downstream of the fuel spray nozzle. A front view of a typical retention head is shown in Figure 2. The purpose of the retention head is to stabilize the flame and to shape the air flow around the fuel spray so that combustion is efficient with minimal pollution. As shown in Figure 2, in addition to the central hole just around the fuel nozzle in the retention head, there are two other zones through which the airflow is directed around the fuel spray. The retention head has many "swirl slots" that result in a central swirl airflow around the fuel spray. Thus the combustion air has both axial and tangential velocity components. The quality of combustion

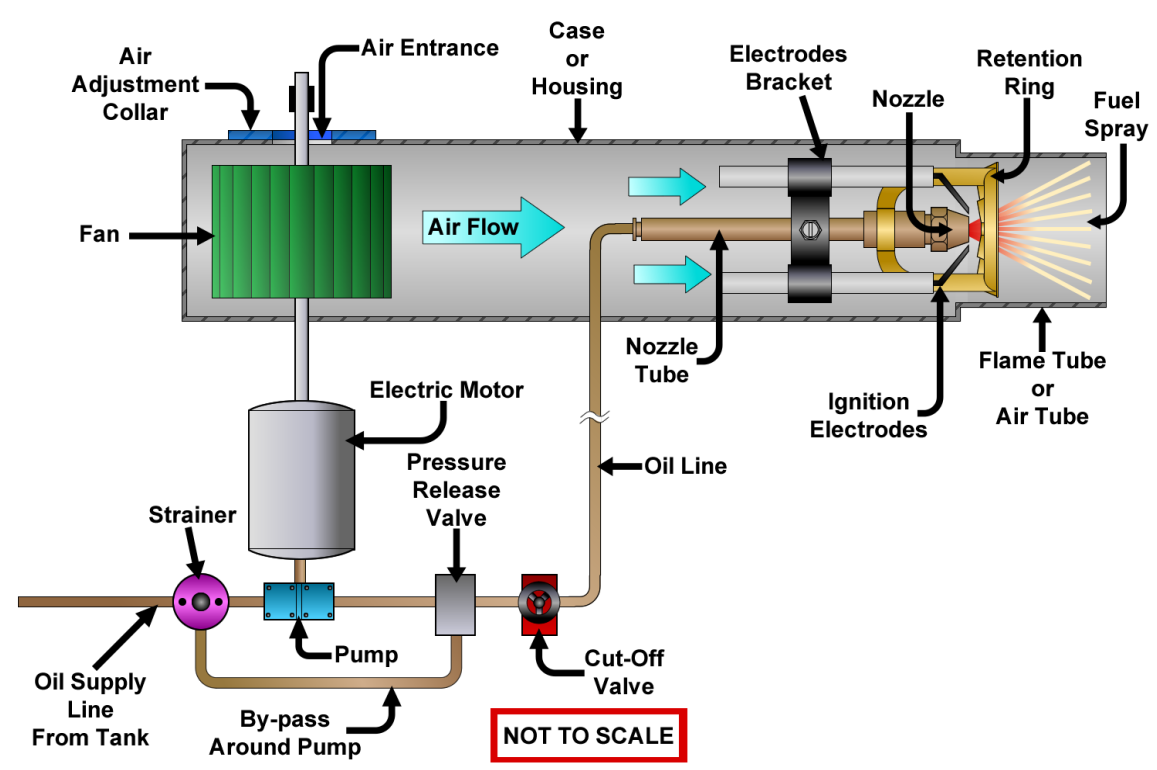

Figure 1. Schematic of a typical oil burner with labeled components.

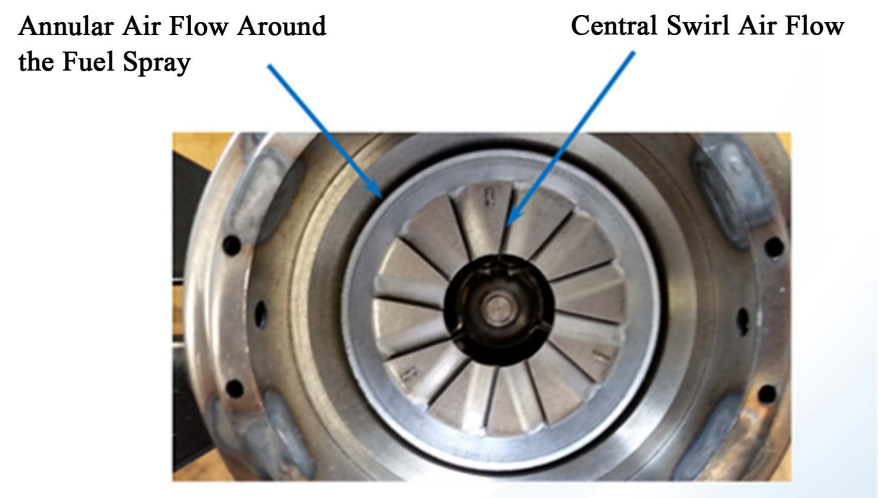

Figure 2. A photograph of an installed oil spray nozzle in the Retention Head of a commercial residential oil burner. 
is not only related to the absolute mass flow of combustion air but also to the magnitudes of the axial and swirl velocity components.

To initiate combustion, an electric spark is provided by the two electrodes that are located close to the fuel spray nozzle. Their optimal location and the spark gap is based on years of research and experience of the burner manufacturers.

Since the fuel spray is axisymmetric, one would assume that for optimal combustion the airflow around the fuel spray should also be axisymmetric. However, as shown by Tutu [1], this is not so in a typical residential oil burner. For example, Figure 3 (from this reference) shows the measured axial velocity distribution at the exit of a typical oil burner. As can be seen in this figure, the measured axial velocity profile is far from axisymmetric.

An obvious question is: what is reason for this departure from axisymmetry when the retention head design is clearly axisymmetric. It was suspected that the distortion in the flow field might be caused by the two ignition electrodes because these seem to be a major source of non-axisymmetric solid objects just upstream of the retention head (Figure 1). If the electrodes are indeed the source of this problem, then a Computational Fluid Dynamics (CFD) analysis for a case with no electrodes should show a perfectly axisymmetric velocity profile at the exit of the retention head. In order to investigate this hypothesis, in the following sections we shall present results from CFD simulations for the following three cases: No Electrodes, the standard two electrodes, and four electrodes. For the four electrode case, the additional two electrodes are merely dummy electrodes (without electrical connections) that make the upstream solid objects a little more symmetric.

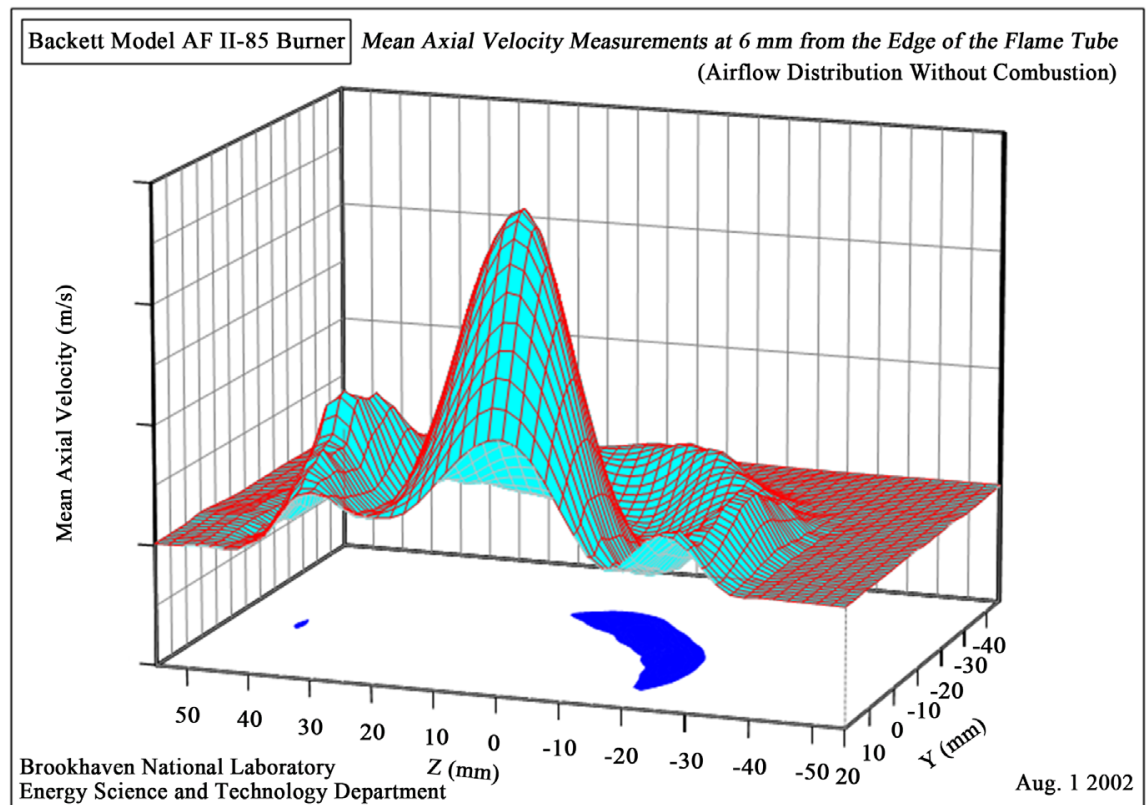

Figure 3. Mean axial velocity measurements at the exit of a retention head oil burner. The dark blue-colored projection on the " $\mathrm{Z}-\mathrm{Y}$ " plane is the region of reverse flow (where the axial mean velocity is negative and hence towards the burner). Thus, the zone of recirculating flow region is very small and far from axisymmetric. 


\section{CFD Flow Simulation of Airflow without Combustion}

\subsection{Computational Domain}

SOLIDWORKS Premium 2016 with embedded SOLIDWORKS Flow Simulation module was used for all simulations. The mesh sizes for these computations ranged from 120,920 to 194,426 . The total CPU time for all the cases was $15 \mathrm{mi}$ nutes. The computations were made on a PC with Intel (R) Core (TM) i7-3770K CPU running at $3.50 \mathrm{GHz}$. The resulting SOLIDWORKS Flow simulations provide the complete velocity field through the system, from the Inlet face to the Outlet face.

A cross-section of the computational domain for the 2-electrode base case (normal burner configuration) is shown in Figure 4. This figure shows the two electrodes, the fuel nozzle and the retention ring. All fluid volume between the inlet face and the outlet face is the computational domain. As shown in this figure, the axial dimension $\mathrm{Y}$ is measured from the downstream face of the retention ring, and the radial coordinate, $r$, is measured from the centerline of the burner. The CFD simulations provide the velocity field throughout the computational domain. However, since our purpose is only to study the axisymmetry of the velocity field immediately downstream of the retention ring, we shall only present the velocity profiles at one downstream location, namely at $\mathrm{Y}=13 / 16$ inches. At this location, we shall present velocity profiles as a function of the radial coordinate, $\mathrm{r}$ for six different values of the tangential coordinate, $\theta$.

In order to eliminate the effect of electrodes on the downstream velocity field we then removed these from our CFD model. The resulting computational domain is shown in Figure 5. Finally, in Figure 6 we show the computational domain for the case of four electrodes. In this case, we have added 2 more electrodes on the side opposite to the existing two electrodes of the base case.

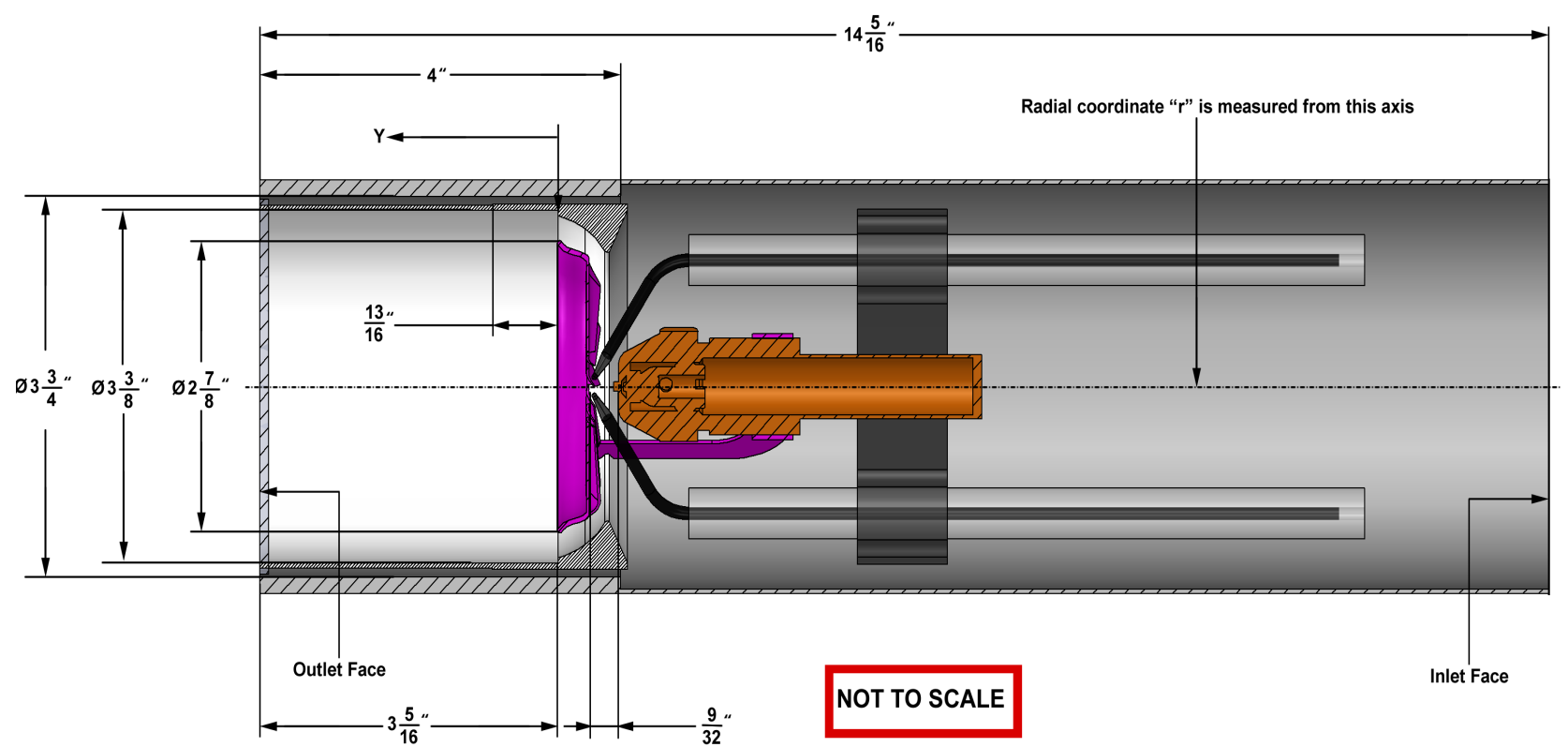

Figure 4. A 2-D rendering of the burner with two electrodes. 


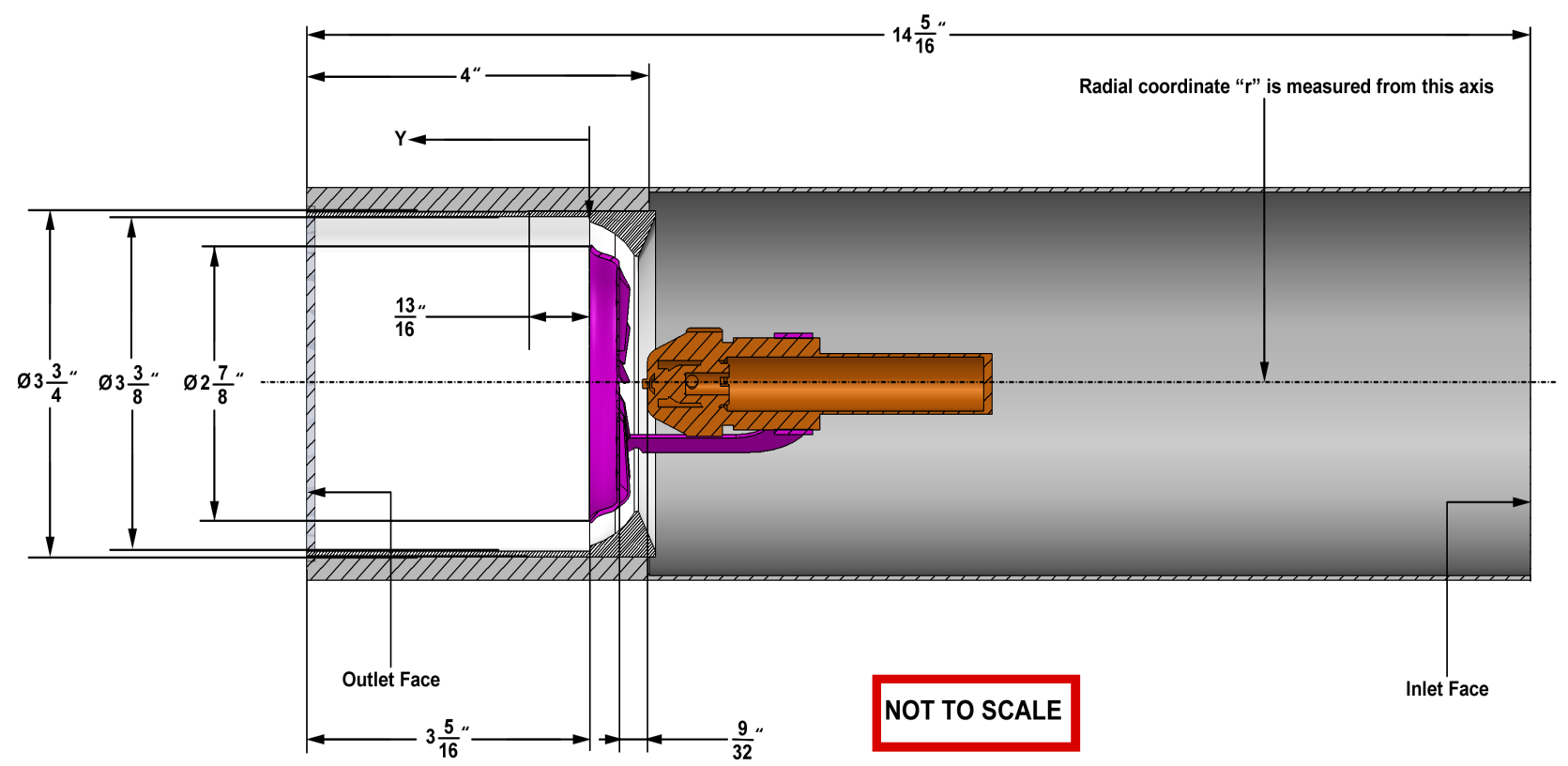

Figure 5. A 2-D rendering of the burner with no electrodes.

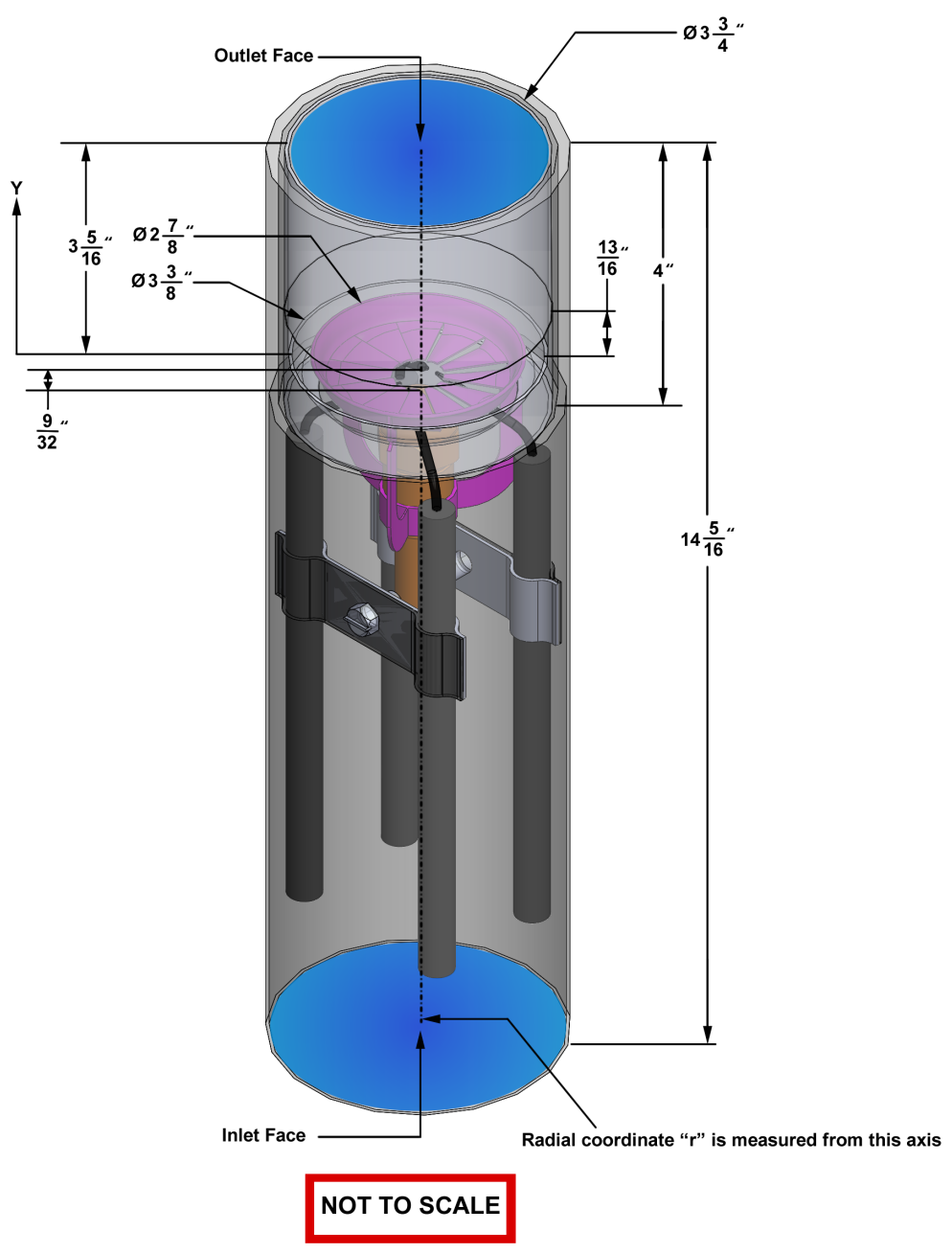

Figure 6. A 3-D rendering of the burner with four electrodes. 


\subsection{Inlet and Outlet Boundary Conditions}

For all CFD simulations, the mass flow rate of incoming air flow was set to $0.0106 \mathrm{~kg} / \mathrm{sec}$ at the inlet face of the computational domain. The temperature of the incoming ambient air was set to $20^{\circ} \mathrm{C}$. Since we are not simulating the fuel spray and combustion, these simulations were run as isothermal without any heat transfer. All solid surfaces in contact with the airflow were treated as real surfaces with friction. At the exit face of the computational domain, we imposed a constant pressure (atmospheric pressure $=101,325 \mathrm{~Pa}$ ) boundary condition.

\section{Results and Discussion}

The computed Cartesian $x-y-z$ velocity components from SOLIDWORKS were transformed into the cylindrical velocity components along $\mathbf{r}$ (radial), $\boldsymbol{\theta}$ (tangential), and $\mathbf{y}$ (axial) directions. Clearly, the vectors $\mathbf{r}$ and $\boldsymbol{\theta}$ are measured from the physical centerline of the burner flame tube. As per usual convention, the angle $\theta$ is measured positive in the counterclockwise direction. However, since the swirl slots are set to produce a clockwise rotation of the airflow, for convenience, we shall consider tangential velocities in the clockwise direction to be positive. We shall first present the mean velocity profiles for the base case (normal burner configuration) of 2-electrodes. These will be followed by the results for the cases of no electrodes and 4-electordes.

\subsection{CFD Results for the Base Case of Two Electrodes}

The computed mean axial velocity profiles at the downstream location of 13/16" from the retention ring for the case with two electrodes along six radial lines are shown in Figure 7. The angle $\theta$ is measured in the anti-clockwise direction from

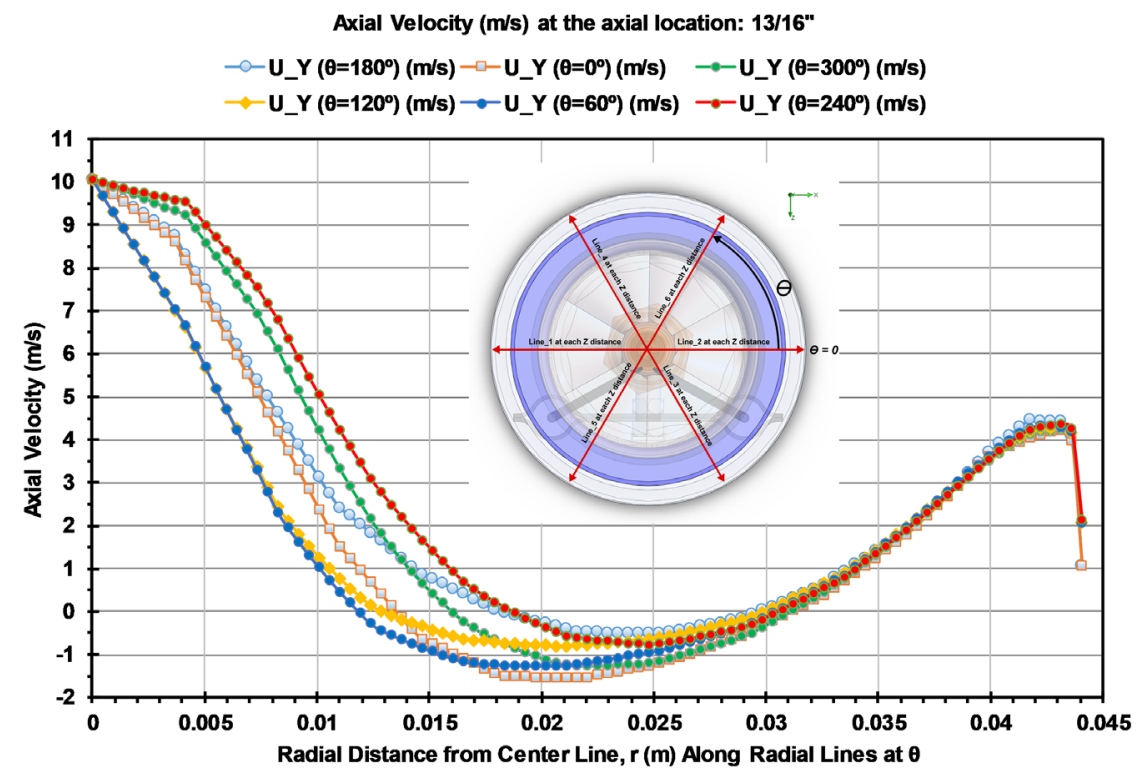

Figure 7. Computed mean axial velocity profiles along six radial lines at the axial location $\mathrm{Y}=13 / 16^{\prime \prime}$ for the case of 2 electrode configuration. In the inset of the above figure, $\theta=0$ is the horizontal radial line from the center towards right direction. 
the radial line corresponding to the horizontal arrow pointing to the right in the inset of Figure 7. If the flow velocities were perfectly axisymmetric, all the six velocity profiles would have collapsed on to a single curve. However, as can be seen, Figure 7 shows a significant departure from axisymmetry.

The corresponding computed mean tangential velocity profiles at the same location are shown in Figure 8. A positive value for the tangential velocity denotes a clockwise direction and a negative value denotes a counterclockwise direction. Again, we see a significant departure from axisymmetry. In particular, we notice a sharp discontinuity for the tangential velocity at the center $r=0$ and significantly large negative values of the tangential velocity for small values of $r$ (near centerline) along some radial lines. This is clearly only possible if the rotational center of the swirling flow is at some distance away from the centerline of the burner. This can be seen more clearly in Figure 9 which shows the velocity vectors on a cross-sectional plane at the same axial location of $Y=13 / 16 "$. As can be seen, the center of the swirling flow is shifted significantly to the left side. Thus the swirling flow is not concentric. This shift, s, was measured to be 0.31 ". When compared to the flame tube radius, $R$, of 1-11/16", the eccentricity, e, of the swirling airflow $=\mathrm{s} / \mathrm{R}=0.184$.

\subsection{CFD Results with No Electrodes}

The computed mean axial velocity profiles at the downstream location of 13/16" from the retention ring for the case with no electrodes along six radial lines are shown in Figure 10. Here we observe that all the six profiles have virtually collapsed onto a single curve, indicating axisymmetry of the axial velocity field. The corresponding computed tangential velocity profiles at the same location are

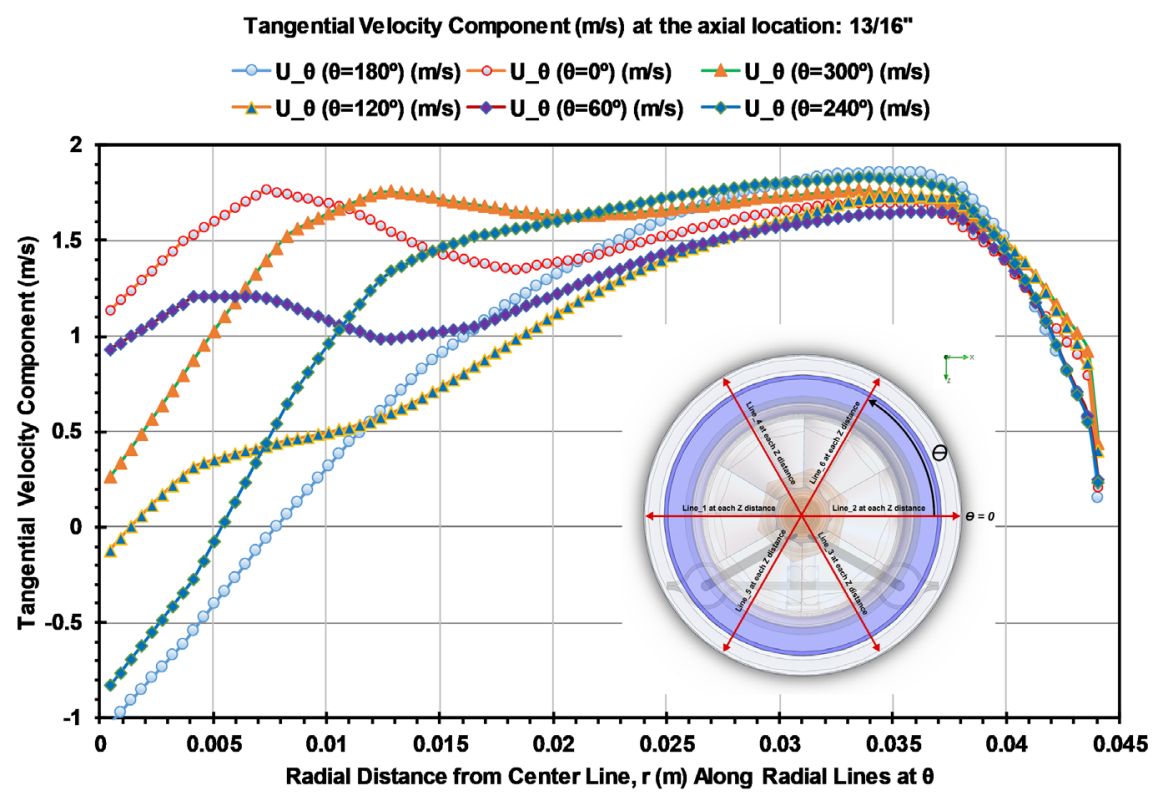

Figure 8. Computed Tangential Velocity profiles along six radial lines at the axial location $\mathrm{Y}=13 / 16^{\prime \prime}$ for the case of 2 electrode configuration. 


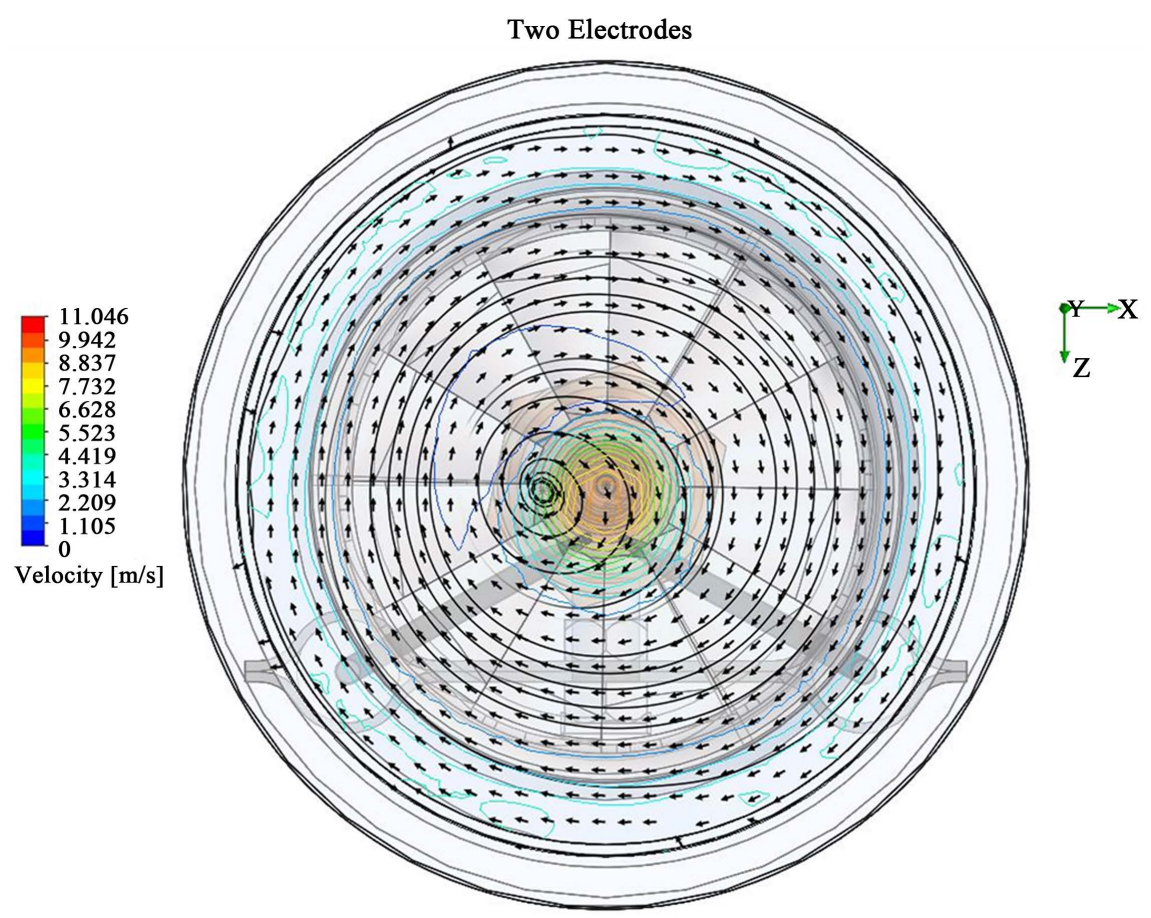

Figure 9. A cross-sectional plot of velocity vectors at the axial location $Y=13 / 16^{\text {" for the }}$ case of 2 electrode configuration. For better visibility, the intensity of the color code for the magnitude of total velocity has been artificially reduced.

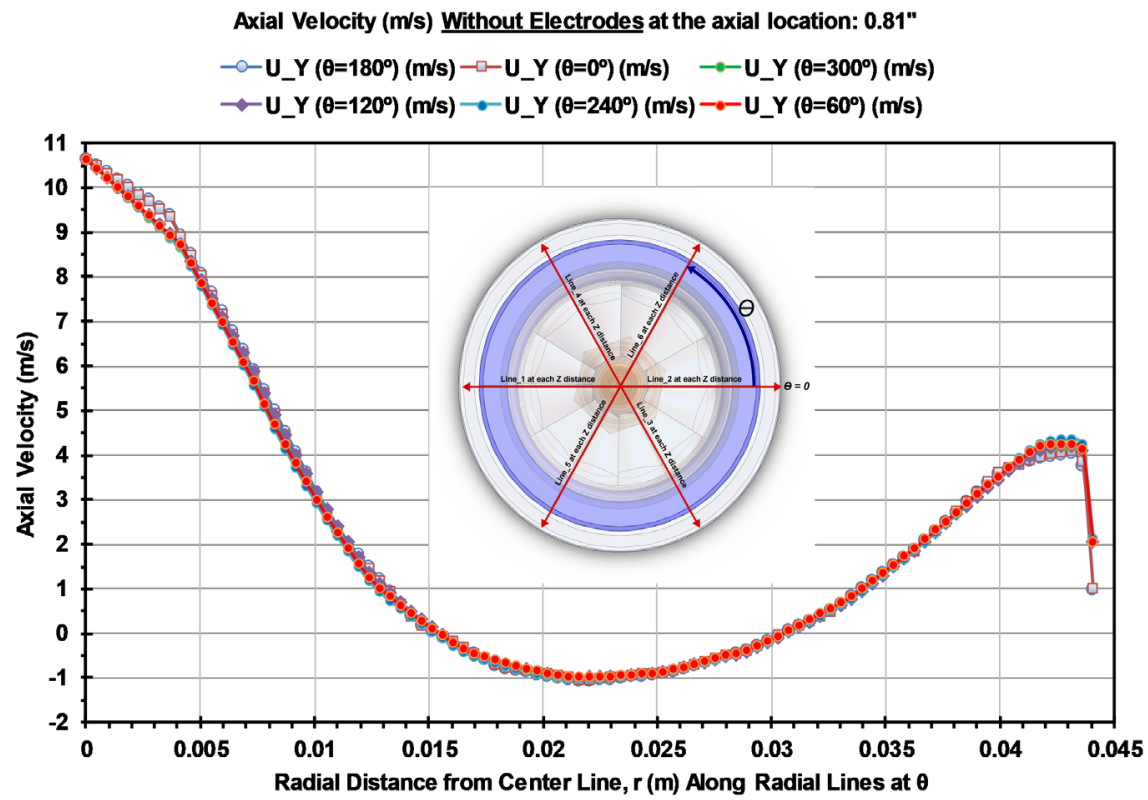

Figure 10. Computed mean axial velocity profiles along six radial lines at the axial location $\mathrm{Y}=13 / 16^{\prime \prime}$ for the case with no electrodes.

shown in Figure 11. Here also we note an almost axisymmetric velocity profile that is a dramatic improvement over the results for the 2-electrode case shown in Figure 8 . The velocity vectors on a cross-sectional plane at the same axial location for this case are shown in Figure 12. Here we see that the rotational center 


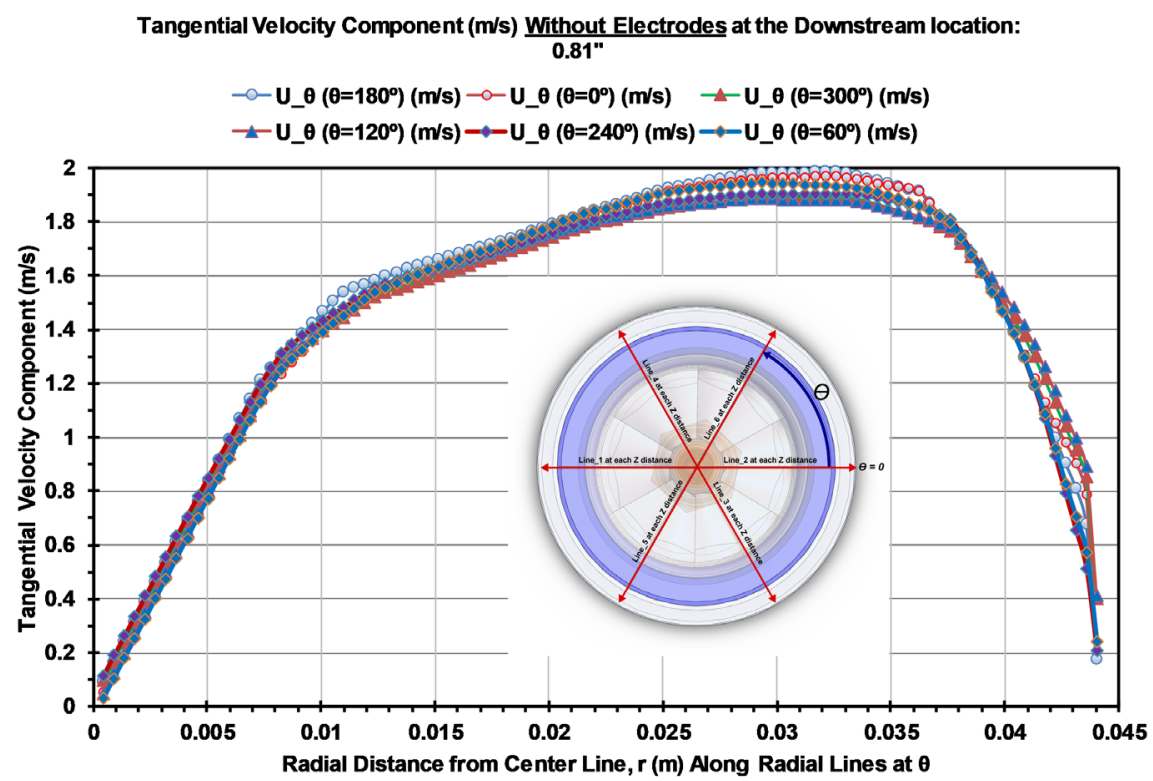

Figure 11. Computed mean tangential velocity profiles along six radial lines at the axial location $\mathrm{Y}=13 / 16$ " for the case with no electrodes.

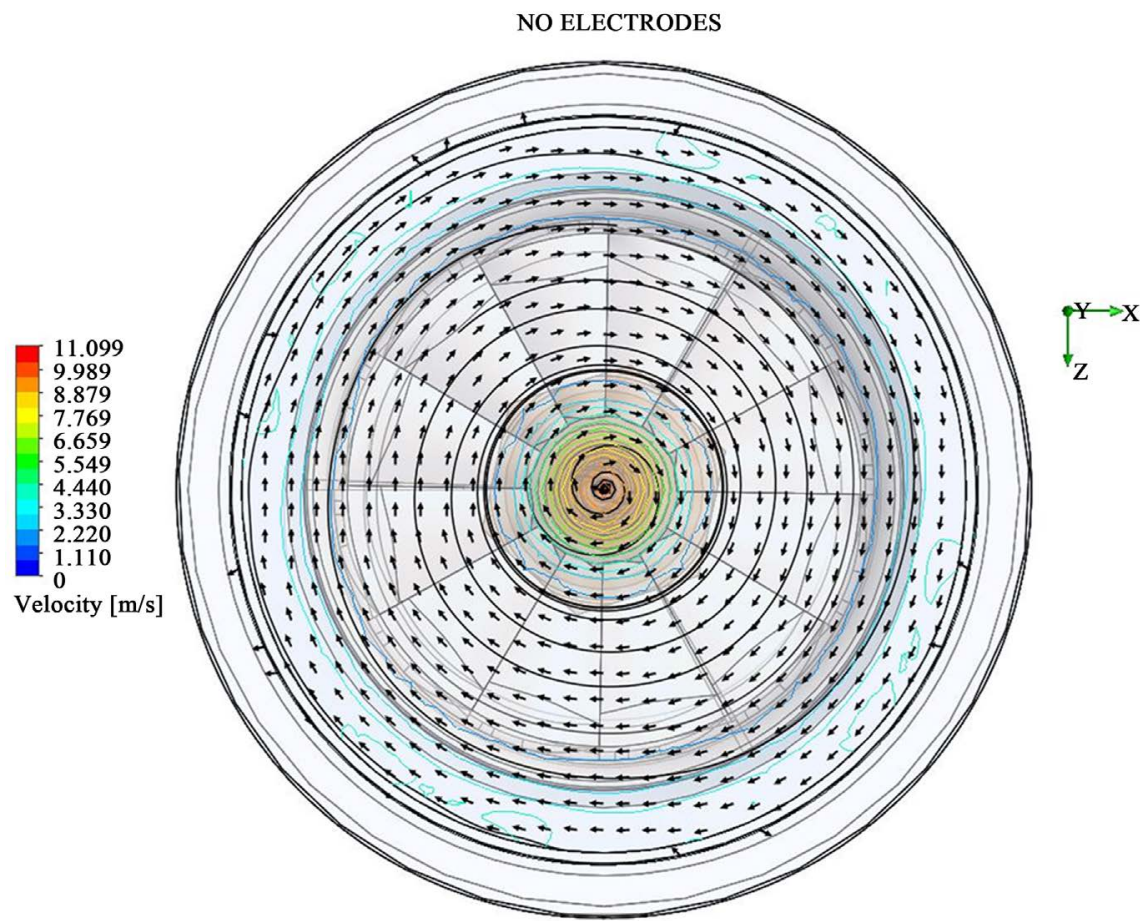

Figure 12. A cross-sectional plot of velocity vectors at the axial location $Y=13 / 16$ " for the case of 2 electrode configuration. For better visibility, the intensity of the color code for the magnitude of total velocity has been artificially reduced.

of the swirling flow coincides with the centerline of the flame tube. Thus it can reasonably be concluded that the two electrodes upstream of the retention ring are a major source of flow field disruption downstream of the retention ring. Nevertheless, electrodes are necessary for combustion initiation, and although 
the objective of the current paper was not to find an alternative electrode configuration that would not distort the flow field, we decided to investigate improvement, if any, in the flow field if we added two more "dummy" electrodes (Figure 6) on the opposite side. The results for this case are presented in the next section.

\subsection{CFD Results for the Four Electrodes Configuration}

The axial and tangential velocity profiles for the case with four electrodes (shown in Figure 6) are presented in Figure 13 and Figure 14. When comparing these results to the base case of two electrodes shown in Figure 7 and Figure 8, we see a significant improvement. For example, in Figure 7 for the two electrode case at location $r=0.01 \mathrm{~m}$ we note the axial velocity variation of $4 \mathrm{~m} / \mathrm{s}$ (from 1 to $5 \mathrm{~m} / \mathrm{s}$ ). The corresponding axial velocity variation at the same $r$ for the case with four electrodes in Figure 13 is noted to be $2 \mathrm{~m} / \mathrm{s}$ (from 2 to 4 $\mathrm{m} / \mathrm{s}$ ), a reduction by a factor of 2 . A similar reduction is also noticed for the reduction in tangential velocity variation when comparing the results shown in Figure 8 and Figure 14. Finally, the cross-sectional plot of velocity vectors for this case is shown in Figure 15. When comparing this to the results for the base case of 2 electrodes shown in Figure 9, we clearly notice that the center of the swirling flow is significantly closer to the physical centerline of the flame tube. The shift in the rotational center of the swirling flow, s, was measured to be 0.11 ", which is lower by almost a factor of 3 when compared to $s=0.31$ " for the case of two electrodes. Thus it is seen that by the simple introduction of two additional dummy electrodes, the flow field axisymmetry can be improved noticeably.

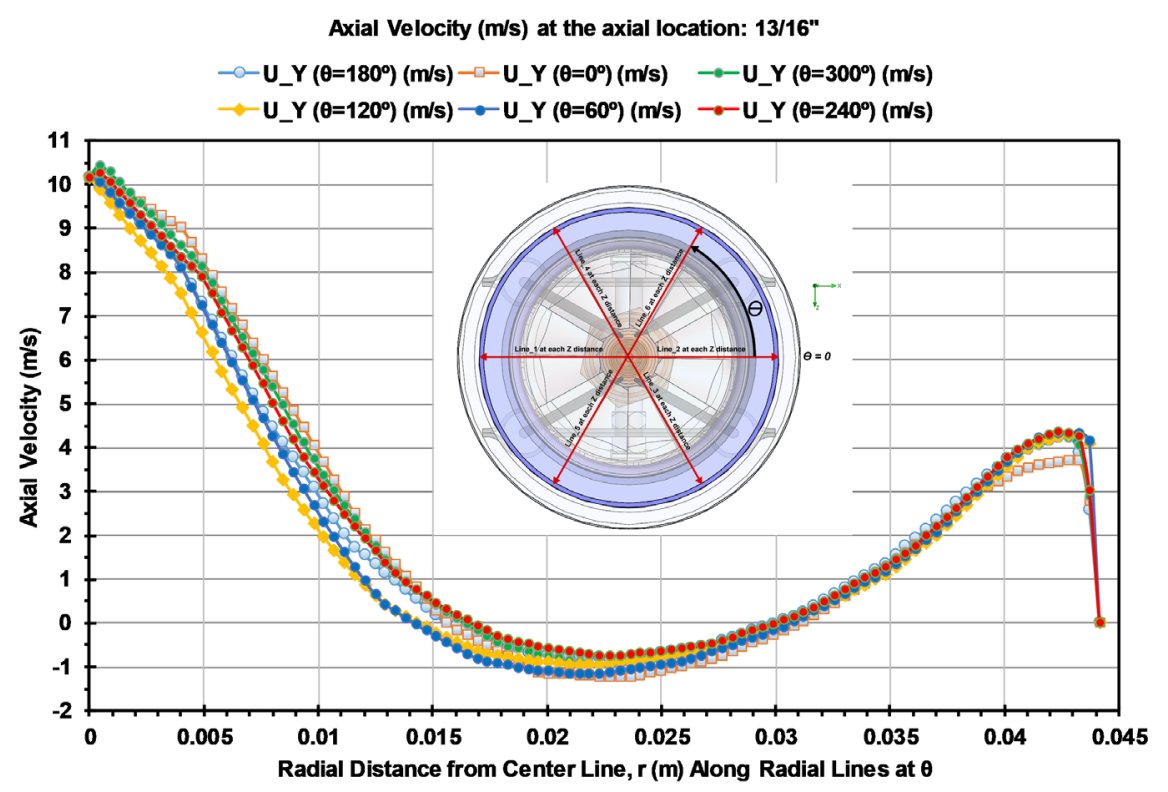

Figure 13. Computed mean axial velocity profiles along six radial lines at the axial location $\mathrm{Y}=13 / 16$ " for the case with four electrodes. 


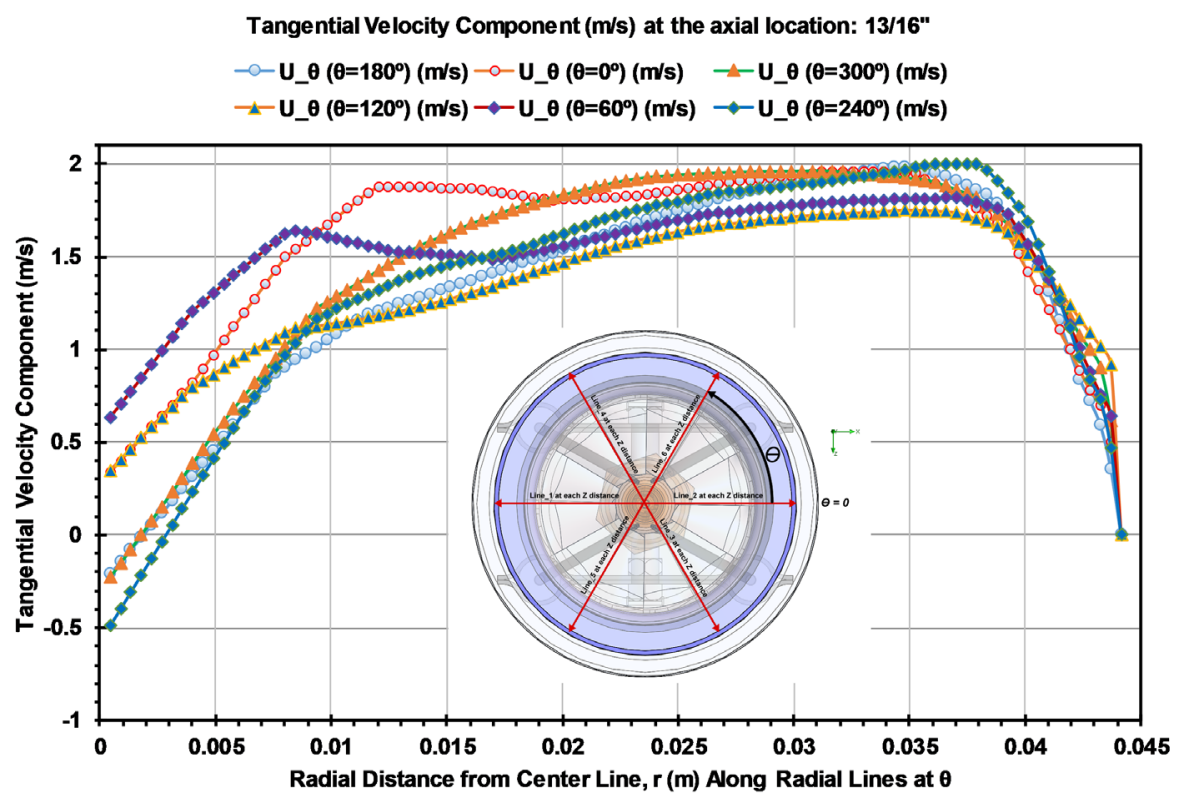

Figure 14. Computed mean tangential velocity profiles along six radial lines at the axial location $\mathrm{Y}=13 / 16$ " for the case with four electrodes.

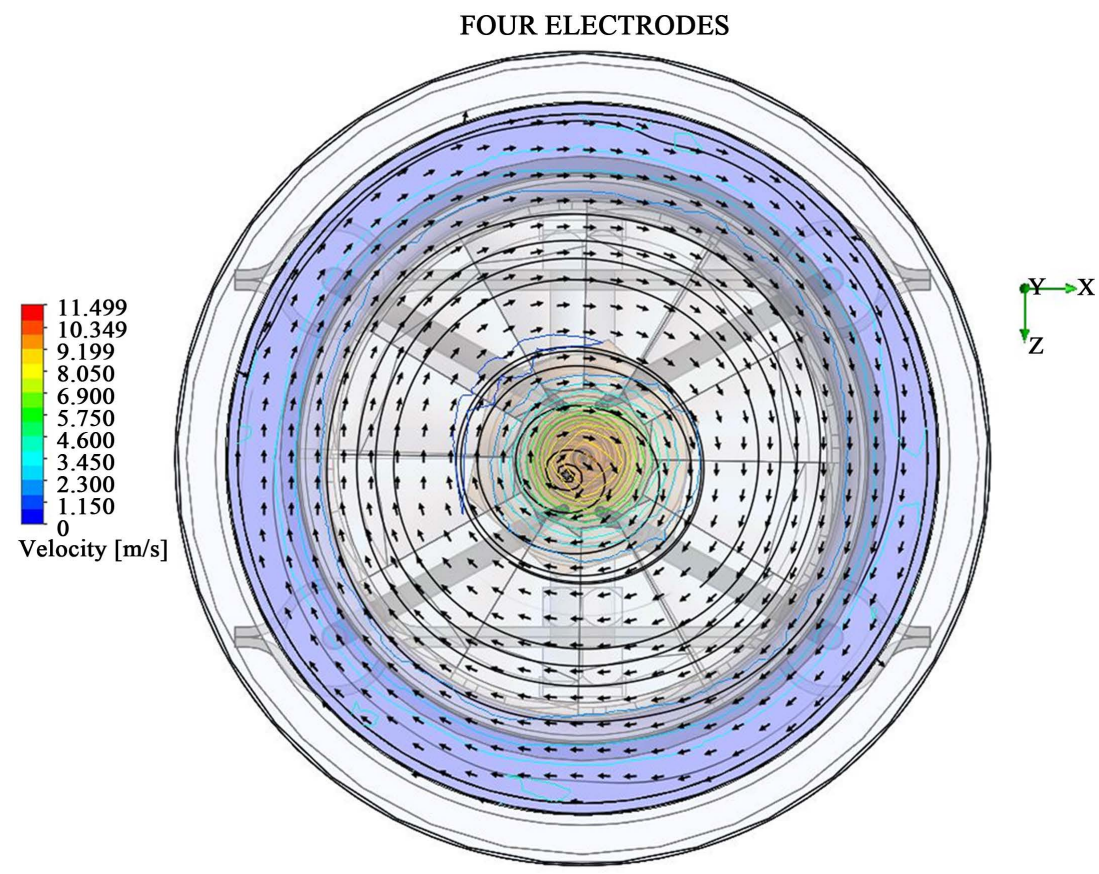

Figure 15. A cross-sectional plot of velocity vectors at the axial location $Y=13 / 16$ " for the 4 electrode configuration. For better visibility, the intensity of the color code for the magnitude of total velocity has been artificially reduced.

\section{Conclusion and Suggested Future Work}

CFD simulations of the air flow through a residential retention head oil burner were performed to investigate the reasons for large departure from axisymmetry in the flow field at the exit of the retention ring. These simulations were made using SOLIDWORKS with embedded SOLIDWORKS Flow Simulation module. 
Table 1. A summary of observations from the CFD Results for the three cases.

\begin{tabular}{ccc}
\hline Configuration & $\begin{array}{c}\text { Eccentricity of the } \\
\text { Swirling Air flow } \mathbf{e}=\mathbf{s} / \mathbf{R}\end{array}$ & Comments \\
\hline No Electrodes & 0 & $\begin{array}{c}\text { Velocity profiles are almost perfectly } \\
\text { axisymmetric. Center of swirling airflow } \\
\text { coincides with the centerline of flame tube. } \\
\text { Large departure from axisymmetry } \\
\text { Two electrodes } \\
\text { Cormal Configuration) }\end{array}$ \\
Four Electrodes & 0.184 & $\begin{array}{c}\text { from the centerline of the flame tube. } \\
\text { Reduces flow distortion by a factor } \\
\text { of } 2 \text { when compared to the } \\
\text { two electrode case. }\end{array}$ \\
& $\begin{array}{c}\text { Center of swirling airflow shifted by } \\
0.11 \text { from the centerline of the flame tube }\end{array}$ \\
\hline
\end{tabular}

$\mathrm{s}=$ Distance between rotational center of the swirling flow and the centerline of the burner flame tube. $\mathrm{R}=$ Inside radius of the burner flame tube.

The simulation was first carried out for the base case of the normal two electrode configuration. Since it was suspected that the non-axisymmetric nature of the two electrodes just upstream of the retention ring might be responsible for the flow distortion, the simulations were carried out for two additional configurations: no electrodes and 4-electrodes. A summary of the observations from the computed results for the velocity profiles are shown in Table 1 . Since the computed velocity profiles were almost perfectly axisymmetric for the case with no electrodes, it is concluded that the presence of two electrodes is indeed responsible for the flow distortion downstream of the retention ring. This distortion results in a swirling axial airflow that is not concentric to the flame tube centerline. The introduction of additional two dummy electrodes on the opposite side seems to reduce the velocity distortion by a factor of 2 . Additional CFD simulations with alternative practical electrode configurations are needed to determine an optimal solution for this problem.

\section{Acknowledgements}

The first author would like to thank the Alabama Louis Stokes Alliance for Minorities Participation (ALSAMP) for their support and Mr. Bennie Mwiinga for his assistance throughout this project. This project was supported in part by the National Science Foundation HBCU-UP Program through award 1818732.

\section{Conflicts of Interest}

The authors declare no conflicts of interest regarding the publication of this paper.

\section{References}

[1] Tutu, N.K. (2002) Cold Flow Measurements at the Exit of a Beckett Model AF II-85 Burner, Private Communication, Brookhaven National Laboratory (BNL) Internal Departmental Memo. 